\title{
LOST IN TRANSLATION? LA ADAPTACIÓN AL CINE DE EL AMOR EN LOS TIEMPOS DEL CÓLERA DE GABRIEL GARCÍA MÁRQUEZ
}

\author{
Miguel Ángel CABAÑAS ENRÍQUEZ \\ Michigan State University \\ mcabanas@msu.edu
}

La película dirigida por el británico Mike Newell (director de Four Weddings and a Funeral) titulada Love in the Time of Cholera (2007) recoge un excelente elenco de actores con premios internacionales: Javier Bardem de España, Giovanna Mezzogiorno de Italia, Catalina Sandino Moreno de Colombia, Benjamin Bratt, John Leguizamo y Héctor Elizondo de los Estados Unidos, entre otros. También la banda sonora incluye canciones de Shakira y la música del brasileño Antonio Pinto, aclamada cantante y ganador de premios por sus composiciones para el cine, respectivamente. Sin embargo, esta ambiciosa presentación cinematográfica de la obra de García Márquez ya consagrada con el premio nobel en literatura y con los elogios de la crítica, con un presupuesto de 50 millones de dólares terminó en un desastre recaudatorio y crítico global.

Este ensayo examina de cerca cómo un producto de Hollywood dirigido al mercado global -y al mercado latino estadounidense con una historia latinoamericana con actores latinos y en inglés-se tambalea recaudando solamente 4.607.608 dólares en el mercado doméstico y 26.729 .976 en el mercado extranjero. Esto contrasta con el éxito rotundo de la novela de García Márquez cuyas primeras ediciones en español vendieron más de un millón de copias, en alemán medio millón, en Francia estuvo en la lista de más vendidos por veinticinco semanas y la versión norteamericana solamente la edición de tapa dura vendió cuatrocientas mil copias (Fahy, 2003: 72). A pesar de tener todos los ingredientes de un filme comercial exitoso, Newell no llegó a cubrir las expectativas económicas proyectadas para la película, ni tuvo una positiva aceptación por parte del público y la crítica. Ambas cosas, argüimos aquí, están relacionadas con el proceso de adaptación. Una hipótesis inicial fue que la película había perdido en la traducción del medio literario al fílmico, o del español al inglés, a pesar de los intentos del proyecto de captar la autenticidad de la obra y desarrollar una traducción audiovisual fidedigna. Este caso demuestra que los intentos de canibalizar productos para consumo global pueden no llegar a buen puerto precisamente por la falta de sofisticación histórica y cultural de la industria de Hollywood. En otras palabras, la perspectiva globalizadora de la producción fílmica intentó reducir la novela a una 
fórmula y domesticar su contenido político o controversial, pero podemos ver cómo esa simplificación no funcionó en términos masivos y al desvirtuar el mensaje subversivo e híbrido del realismo mágico, proveniente del contexto postcolonial, la película no consiguió reafirmar la 'autenticidad del texto' para el público de la adaptación. En los Estados Unidos, la película no conectó con el trabajador latino de a pie de origen mayoritariamente mexicano o centroamericano y tampoco ofreció un producto al gusto del público lector global; Sin contar que el uso del inglés en la película parecía forzado para unos y para otros el acento exagerado de los actores tocaba lo caricaturesco. Más allá de esos detalles formales, la propuesta de este ensayo es que el problema fundamental se encuentra en la idea inicial de adaptación de los productores, director y guionista de presentar una historia de amor realista como intento hollywoodense de amarrar la narrativa de la novela como una historia de amor típica a lo Romeo-and-Juliet o imitando la fórmula del historical romance. Es más, lo paradójico no es precisamente que hicieran una adaptación libre del libro, sino que, en su intento de ser fidedignos al texto original, copiando minuciosamente las escenas, la ambientación y las líneas poéticamente memorables, el guionista, el director y el productor pierden de vista las ambivalencias en la historia y los personajes, así como la parodia del realismo llevada a cabo mediante el uso de un narrador no fidedigno que construye y deconstruye discursos. Es como si la novela deconstruyera el realismo fílmico antes de que se hubiera hecho imagen en la película.

Ambos, el director Michael Newell y el guionista Ronald Wood, tenían anteriormente mucha experiencia con la adaptación: Ronald Wood ganó en el 2003 un Óscar por Best Adapted Screenplay en The Pianist (2002) y Newell había adaptado con éxito literatura al cine en sus películas Enchanted April (1992) y Harry Potter and the Goblet of Fire (2005). Por supuesto, se podría pensar que su limitación puede ser lingüística y cultural, pues desconocen el mundo latinoamericano y por supuesto el idioma español. ${ }^{1}$ Según la reseña de Lisa Schwarzbaum, alguien como Alfonso Cuarón hubiera sido un mejor director para captar las peculiaridades de García Márquez: "But working with a toneless movie script by Ronald Harwood, fellow Harry Potter director Mike Newell, alas, doesn't" (Schwarzbaum, 2007). En una entrevista con NPR, del 13 de noviembre del 2007, Newell explica su intento de ser totalmente fidedigno a la novela:

Well, it is a sacred text, and it is a sacred text in Spanish and we were going to make it in English. Because the finance for the film came from Hollywood, and he who pays the piper calls the tune. So, English it is. [...] It is extraordinarily rich. It is a great piece of art, because every sentence is contributing in some way, it is not just a forth-going simple narrative, it weaves back and forth. Marquez, when he saw the first draft of the script, he sent us 7 pages of notes, which I had taped on my office wall for six months, which was a kind of Bible to me. The one that sort of sang out at me was "Where is my stitch work?" [...] One of the ways that I have tried to address it was that no frame of the film, no picture, would ever tell just only one story, I always tried to have two stories going at the same time.... It is not a literary device... that is a cinematic device («Love in the Time of Cholera Adapted to Screen», 2007).

\footnotetext{
${ }^{1}$ En los extras del DVD, se deja en evidencia el desconocimiento general sobre Colombia en una conversación entre el productor Scott Steindorff y el guionista Ronald Wood, este último le pregunta a Steindorff que quién es Shakira. También Steindorff anteriormente queda en evidencia de que realmente no conocía la obra de Gabriel García Márquez.
} 
Para Newell, el texto literario tiene precedencia y él subordina su papel como secundario frente a ese texto que el denomina "sagrado" en la entrevista. Mientras la crítica de la adaptación rechaza la noción de fidelidad, como explica Simone Murray, "fidelity models remain prevalent in film and television reviewing, in cultural journalism, and in everyday evaluations by the film-going public" (2012: 8). El público mantiene unas expectativas de fidelidad que hace que la industria todavía tenga en mente la necesidad de establecer ese aspecto de autenticidad. Siguiendo las ideas de Pierre Bourdieu sobre el campo de producción cultural el discurso de fidelidad a la obra literaria proviene de una correlación y coexistencia entre la ganancia económica y la ganancia simbólica de conseguir una 'traducción fidedigna' de un producto cultural, ya que el autor ya tiene el capital cultural que reafirma la adaptación y la promueve (Bourdieu, 1993: 48). Por esto, Newell intenta traducir la idea del bordado literario al espacio cinematográfico mediante la inserción de dos historias paralelas, pero no parece entender a lo que se refiere el autor con 'entretejidos textuales' ['stitch work']. Según la entrevista, Newell cree que el autor se refiere al desarrollo de los personajes y cómo se transforma interminablemente estos en el texto. Newell, por su parte, se atiene a la idea de 'película romántica de época' intentando reproducir el ambiente perfectamente y de forma realista y fidedigna. Según Brian McFarlane, este tipo de adaptación representa "exhaustive attempts to create an impression of fidelity to, say Dickens's London or to Jane Austen's village life, the result of which, so far from ensuring fidelity to the text, is to produce a distractive quaintness" (1996: 9). McFarlane deja sentado que los estudios sobre la adaptación que promulgan que el cine tiene que ser fiel a la novela pierden la oportunidad de entender la relación entre ambos medios, así como los estudios que toman al cine como artefacto cultural independiente del objeto literario. La idea de que ambas tienen que ser iguales o la película tiene que ser una copia de un original evita ver lo que Robert Stam ha definido como 'intertextual dialogism' o «the infinite and open-ended possibilities generated by all the discursive practices of a culture, the entire matrix of communicative utterances within which the artistic text is situated, which reach the text not only through recognizable influences, but also through a subtle process of dissemination» (Stam, 2000: 64).

En otras palabras, Stam reconoce que la relación entre cine y literatura es abierta, multidireccional e intertextual y por tanto abre la posibilidad de entender la relación entre adaptación y texto literario más allá de la fidelidad. Como James Naremore apunta "there is a conflict that exists between the model of translation of text to film that demands "fidelity" on the one hand, and the model of performance that demands 'a unique signature' on the other" (2000: 1-16). Esto nos deja entrever la tensión entre el acercamiento fiel que plantea Newell y la diferenciación original de uno y del otro producto cultural.

El guionista cinematográfico también concibe la historia como la base para una película de amor. En una entrevista en el programa All Things Considered de NPR antes del estreno, Ronald Hardwood explica su visión del guión de Love in the Time of Cholera:

What goes through my mind whenever I have to adapt anything is — especially with a long workwhat do you leave out? That seems to be the crucial thing. The first decision, though, is what is the book 
about. What are you going to make for film about? It can't just be a great sprawling epic event. It has to have a central theme. And I decided that it was a mystic, extraordinary love story, which I think it is. And I think Gabriel Garcia Marquez thinks the same. When he calls it humane, that's why because it's about love (“Screenwriter Adapts 'Love' for the Silver Screen", 2007).

Hardwood entiende que el tema principal es el amor y simplifica la complicada y laberíntica narración del libro, apoyándose en las palabras ambiguas del autor. También, Hardwood cree que la representación del tema es 'realista': "There's no magical realism in Love in the Time of Cholera. And people think there is. Somebody said to me the other day, how do you deal with magical realism? Obviously, they haven't read the book because there isn't. It's a very realistic book" ("Screenwriter Adapts 'Love' for the Silver Screen”, 2007). Su perspectiva es clara y rotunda: la historia es de amor desde la perspectiva realista sin la visión hiperbólica del realismo mágico. Pero nos surgen preguntas sobre la trama: ¿Cómo es posible que después de lo que sabemos del matrimonio entre Juvenal y Fermina que las últimas palabras de juvenal afirmen un amor puro y completo? ¿Cómo es posible que después de acostarse con 622 mujeres, todavía Florentino sea "virgen"? Como explica Ana María Manzanas, "Whereas realism depicts one possible 'horizontal' world that coincides with the tangible, the verisimilar, and the so-called "objective," magical realism presents a multifaceted and multilayered reality and history that allow a vertical perspective" (2009: 51). A pesar del cuidado de Harwood de incorporar frases memorables del libro, la película nos ofrece una versión de la historia que elimina todo los aspectos inverosímiles, mágicos y misteriosos del texto.

Sorprende esta concepción 'realista' tajante de la obra con la opinión que tiene la crítica y la lectura popular de García Márquez que presenta el realismo mágico como la 'marca' del autor. Esta marca estilística de autenticidad autorial es, sin duda, lo esperado por el público, y sin embargo, el guión evita la pregunta de 'irrealidad' o 'magia' que puede plantear el universo garcimarquiano. El realismo mágico es la capacidad narrativa de dar verosimilitud interna a lo fantástico e irreal. Stephen Hart lo ha definido de la siguiente manera:

García Márquez's fictional world is a water-tight universe where everything obeys its own logic. The consistency of the world that the Columbian [sic] novelist presents us with is suggested by the fact that, not only is the supernatural depicted as if it were natural, but the natural is presented as if it were supernatural. Marquez's fictional world, therefore, neither follows the laws of the supernatural exclusively nor the laws of the natural exclusively, but bodies forth a dynamic fusion of both. The growth of the scientific spirit of enquiry in the West, which has dominated all fields of knowledge for the past centuries, tended to make us think of the world as an objective phenomenon, which can be tested and understood according to rational and empirical criteria. Cien años de soledad, however, deliberately subverts this trend toward rational objectivity (Hart, 1982: 47)

Es imposible entender la práctica del realismo mágico sin la experiencia postcolonial y su crítica al conocimiento occidental. Por tanto, la eliminación de este aspecto hace desparecer su mensaje a la vez que trastoca su 'marca de autenticidad'.

Aunque la obra paradigmática del realismo mágico sea Cien años de soledad, no tiene porque estar presente en El amor en los tiempos del cólera. En contraste con la tajante visión de Hardwood, una mirada de cerca al texto nos ofrece la posibilidad de ver cómo García Márquez plantea la 
inverosimilitud y la hipérbole típica del realismo mágico en el desarrollo de esta historia. Un ejemplo concreto sería la muerte del doctor Urbino que intenta atrapar a un loro encaramado en un mango:

No habían logrado alcanzarlo en tres horas. Las sirvientas ayudadas por otras del vecindario habían recurrido a toda suerte de engaños para hacerlo bajar, pero él continuaba empecinado en su sitio, gritando muerto de risa viva el partido liberal, viva el partido liberal carajo, un grito temerario que les había costado la vida a más de cuatro borrachitos felices (García Márquez, 1985a: 40).

El loro, un animal extravagante que habla en varios idiomas incluido el francés, desde el árbol se burla del doctor con gritos políticos. Esto representa un momento increíble y hasta inverosímil que trae la muerte de Juvenal al subirse a una alta escalera para hacerlo callar. El narrador nos presenta esto sin ningún tipo de ironía sino con un tono de seriedad que presenta lo inverosímil como parte de lo real.

Aparte del amor idealizado que sobrepasa el tiempo y el espacio, en la novela pasan cosas extrañas que se explican como si fueran realidades misteriosas. Por ejemplo, se manifiesta lo fantasmagórico especialmente en el viaje de Florentino y Fermina en el río Magdalena hacia el final del libro. Ella tiene esta experiencia:

El único ser que se vio desde el buque, fue una mujer vestida de blanco que hacía señas con un pañuelo. Fermina Daza no entendió por qué no la recogían, si parecía afligida, pero el capitán le explicó que era la aparición de una ahogada que hacía señas de engaño para desviar los buques hacia los peligrosos remolinos de la otra orilla. Pasaron tan cerca de ella que Fermina Daza la vio con todos los detalles, nítida bajo el sol, y no dudó de que en realidad no existiera, pero su cara le pareció conocida (García Márquez, 1985a: 440).

Esta aparición es presentada simultáneamente como real e irreal, como verosímil e inverosímil. Sin embargo, la narración no toma partido, unas palabras apuntan hacia lo real, "la vio con todos los detalles, nítida bajo el sol", mientras otras nos dan a entender que se trata de "la aparición de una ahogada". El misterio todavía permanece porque su "cara le pareció conocida". Ambas técnicas de crear una ambigüedad que raya en la inverosimilitud y la aparición de lo fantasmagórico que apunta hacia el cuestionamiento del realismo son elementos que adentran la narración, sin avisar, en el mundo del realismo mágico.

La presencia de la historia y el triángulo de amor contribuyen a que Newell entienda la narración como un 'national historical romance' por eso se presta especial atención al vestuario y sobre todo al contexto histórico de las calles de Cartagena. Este malentendido de Newell de concebir la novela de García Márquez como una novela histórica proviene del contexto de la novela misma que retoma la aparición del cólera en Colombia y el desarrollo de la comunicación fluvial en los ríos continentales, la llegada de la electricidad a las zonas urbanas en Colombia, y la guerra entre facciones políticas. Doris Sommer ha denominado este tipo de historia, 'ficción fundacional': "Romantic novels go hand in had with patriotic history in Latin America. The books fueled a desire for domestic happiness that runs over into dreams of national prosperity; and national building projects invested private passions with public purpose" (1991: 7). Claramente, El amor en los tiempos de cólera se nutre del romance histórico, pero éste se transforma en una parodia de sí mismo: Se convierte en una presentación de proyectos fundacionales nacionales que se deconstruyen sistemáticamente a través de la hipérbole, la 
ironía y la burla en la narración. Como explica Sommer: "By the 1960s novelists were scorning this habitual naturalization of history. The Boom tried to demolish or trivialize the "mythic" subtext of national development, letting it peek through the discursive debris as risible simulacra" (1990: 72). Lo que está haciendo García Márquez, como miembro del grupo de escritores del Boom en la novela, es precisamente parodiar esas narrativas históricas y héroes nacionales. Es por eso que los personajes de la novela salen mal parados frente al lector: ni Fermina, ni Juvenal, ni Florentino son al fin y al cabo héroes sino personas mezquinamente guiadas por sus circunstancias sociales y por eurocéntricas concepciones de la nación y de la cultura. Sin duda, Newell confunde una obra de época realista al estilo Charles Dickens con la paródica y burlona obra de García Márquez. El mismo autor colombiano explicó su visión de la historia y su representación específicamente en El amor en los tiempos del cólera en una entrevista con Raymond Williams:

[...] because I don't write with historical rigor. Someone could figure out, for example, that Victor Hugo and Oscar Wilde couldn't have been in Paris at the same time. It's not that these are anachronisms or accidents but that I had no desire to change a detail I liked just to make the chronology function properly. This novel isn't a historical reconstruction. Rather, it contains historical elements used poetically. All writers do this (Williams, 1989: 136).

Su visión histórica es ciertamente de tipo realista-mágica en el sentido de que hay coincidencias mágicas que suceden y necesariamente obtienen nuevos significados. Todo es posible mientras responda a su concepción poética de la historia que concuerda con la visión de García Márquez de transformar el significado de la realidad a través de la ficción.

Sabemos que Newell construye la narración como un triángulo de amor y elimina el tema presentado al comienzo de la obra que es la vejez y la muerte. También elimina un aspecto importante en la obra de García Márquez que es la persistencia de la violencia en la sociedad colombiana, y por extensión, la latinoamericana. El tráiler anuncia esta perspectiva: "This holiday season comes the greatest love story ever told, based on a novel by Nobel Prize-winning author Gabriel García Márquez [...] Experience a love story that spans a lifetime, beyond wars and tragedies, to give a lost love a second chance" ("Love in the Time of Cholera - Trailer"). En cuanto al tema de la vejez, el libro enmarca la trama con la muerte de Jeremiah de Saint-Amour, un refugiado antillano que juega al ajedrez con Juvenal Urbino. La primera página nos narra su muerte y suicidio. Se va desarrollando una dicotomía entre el suicidio por amor y el suicidio de Saint-Amour que ha sido para evitar la vejez: "Y sólo decirlo cayó en la cuenta de que entre los incontables suicidios que recordaba, aquel era el primero con cianuro que no había sido causado por un infortunio de amores" (García Márquez, 1985a:14). Este personaje es una de las cosas que eliminaron en la película porque no parece tener nada que ver con el triángulo de amor, pero es precisamente lo que precipita la muerte de Juvenal y encuadra la historia para sugerir que la historia no es sobre el amor (perdido), sino sobre el ridículo intento de recuperar la juventud perdida. Urbino responde que la razón del suicidio es 'gerontofobia' o el miedo a la vejez (García Márquez, 1985a: 58). Esta muerte afecta a Juvenal y le hace recordar su experiencia del pasado. Como Gene Bell-Villada afirma: 
For the second larger theme in Love in the Time of Cholera is that of aging and its difficulties, a process not easily romanticized. García Márquez in his interviews concerning Love mentions having read Simone de Beauvoir's The Coming of Age (in the British edition, Old Age) and his novel is consciously and profoundly informed by the Frenchwoman's classic study of the subject. Love narrates, as de Beauvoir first does, the physiological changes typically accompanying aging" (Bell-Villada, 1990: 193).

A pesar de coincidir con Bell-Villada que la vejez es un tema importante, el análisis de la historia deja claro que la vejez y el amor son temas entrecruzados y por tanto no pueden ser uno primario y el otro secundario. Teniendo presente que de Beauvoir puede ser un subtexto de El amor en los tiempos del cólera, entonces nos damos cuenta que la pérdida de la memoria y la sensación de la ausencia del paso del tiempo propios de la vejez son elementos cruciales para entender la historia. Saint-Amour también nos presenta las historias de fondo sobre amores prohibidos ya que Juvenal tiene que ir a ver a su amante negra para entregarle la última carta y las pertenencias de Saint-Amour. Esta historia prefigura la historia de pasión y el amorío fuera del matrimonio de Juvenal con una mulata llamada Barbara Lynch (Hart, 2010: 133) y establece a Juvenal y a Saint-Amour como dobles. Al eliminar esos detalles en los que el libro complica las relaciones y rescribe versiones contradictorias de lo sucedido, obligándonos a leer and releer más incisivamente, la película simplifica su contenido postcolonial y sus temas más complejos. El libro está lleno de misterios sin explicación y en un sentido metafórico, el cólera también esconde la memoria de las guerras y la violencia que no se reconoce como tal en una sociedad aparentemente en paz. Solamente vemos vislumbres de esa guerra y los muertos son ambiguamente víctimas del cólera.

El amor de Florentino no es heroico sino exagerado. Como apunta Mark I. Millington, "Florentino's first [impassioned letter], in which he declares his love, reaches sixty double-sided sheets. This sheer excess is a sign of the hyperbolic nature of his emotions, which is always full throttle but also always a closely guarded secret" (2010: 117). Este amor caprichoso que contiene un exceso, parece más enfatizado con la vida sexual de Florentino que hace el amor con más de seiscientas mujeres para acallar su pasión. Este amor calenturiento se contrasta con el amor de conveniencia entre Fermina y Juvenal. En la novela, la relación entre Fermina y Florentino se desarrolla como una historia de seducción. Florentino, durante los años en los que no tiene acceso a Fermina, manda poemas de amor al concurso anual de poesía para que Fermina lea su nombre en público. El juego es el de un don Juan obsesionado con su rechazo, más que el de un enamorado eterno. Como ha afirmado Mabel Moraña, "Fermina acts both as nexus between the two male characters and as a stabilizing mechanism because of her ability to operate in both registers and to use time in her favor" (31). Sin embargo, en la película, se intenta vender la noción de un amor puro, eterno, y verdadero que no funciona con la figura de antihéroe de Florentino. Como tal, el cólera representa la confusión del amor con el sexo y la novela nos da muchos tipos de amor que no necesariamente coinciden con el amor romántico idealizado como es el caso de Leonora Cassiani, la mulata que se convierte en la amiga y confidente de Florentino después de la muerte de su madre. Una vez más el tema postcolonial de la raza se pierde en las entrañas del realismo fílmico de la película. 
Un alto porcentaje de películas producidas en los Estados Unidos son adaptaciones, en parte porque las adaptaciones son las que más recaudan en la industria cinematográfica hollywoodense. Históricamente, durante los años del 1994 al 2013, aunque 51\% de las películas fueron adaptaciones, solamente $25 \%$ son adaptaciones provenientes de la literatura (StephenFollows.com, 2014) ${ }^{2}$. Las adaptaciones son importantes en el mercado global de películas puesto que ofrecen historias conocidas ya por miles de lectores, y por tanto, pueden ser más fáciles de promover, para un público predispuesto a ver cómo el cine adapta esos comics, obras literarias, e incluso videojuegos que tanto les agradan. Por otro lado, las adaptaciones pueden crear la demanda del producto cultural visual, pero al mismo tiempo puede crear ciertas expectativas en el público difíciles de alcanzar.

Por esta razón, los productores, el director y el guionista desde el comienzo estaban obsesionados con ser totalmente fieles al original de García Márquez. Tal vez, si hubieran intentado transformar la historia del todo sin ser tan fieles al contenido de ciertas escenas o la construcción histórica, hubieran conseguido hacer una versión más interesante. Su interés en poder decir que está basada en la novela tiene que ver con el éxito comercial global que anhelan, usando el nombre mágico de un autor best seller y dueño del pedigrí del Nobel de Literatura. La postura de la industria cultural se concentra en las ganancias de los productos que crean. Como nos comenta Deborah Cook, Theodor W. Adorno ya había presentado el concepto de 'culture industry'; Cook afirma: "Far from being a culture by and for the masses - as the older folk and popular cultures once were - the culture industry is geared to profitmaking, controlled by centralized interlocking corporations, and staffed with financial experts, management and production teams, technicians, "star" reporters, writers, actors, musicians, and other creative talent” (1996). García Márquez, que trabajó como guionista e incursó en el mundo del cine, reconoce la presión que la maquinaria pone en el escritor de cine:

En realidad, el destino del escritor de cine está en la gloria secreta de la penumbra, y sólo el que se resigne a ese exilio interior tiene alguna posibilidad de sobrevivir sin amargura. Ningún trabajo exige una mayor humildad. Más aún: debe considerarse como un factor transitorio en la creación de la película, y es una prueba viviente de la condición subalterna del arte del cine. Mientras éste necesite de un escritor, o sea del auxilio de un arte vecino, no logrará volar con sus propias alas. Ese es uno de sus límites. El otro, y todavía más grave, por supuesto, es su compromiso industrial. El propio director termina por darse cuenta, tarde o temprano, de que tampoco es mucho lo que él puede hacer dentro del estrecho margen de creación que le dejan las cuentas del productor, por un lado, y los fantasmas prestados del escritor, por otro (García Márquez, 1985b: 103).

El entusiasmo inicial de García Márquez por el cine termina desilusionándolo y como comenta en su artículo publicado en 1982 sobre su involucración con el cine durante unos años culmina en la escritura de su obra más importante a partir del año 1965, Cien años de soledad. el escritor explica: "En aquella travesía del desierto comprendí que no había acto más espléndido de libertad individual, que sentarme a inventar el mundo frente a una máquina de escribir" (García Márquez 1985b: 105). Esto, en cierta manera, romantiza la idea del autor solitario creando su novela en su estudio y enturbia

\footnotetext{
${ }^{2}$ Según Stephenfollows.com, "[b]etween 1994 and 2003, original screenplays outnumbered adaptations every year but one, whereas in the following decade (2004-2013) the opposite was true, with adaptations outnumbering original screenplays in eight of the ten years" (Stephenfollows.com, 2014).
} 
como el libro "is demonstrably as much the product of institutions, agents and material forces as is the Hollywood blockbuster" (Murray, 2012: 13). Por ejemplo, sabemos que Carmen Balcells fue instrumental como agente literaria de la mayoría de los escritores del Boom incluidos Augusto Roa Bastos, Carlos Fuentes, Vargas Llosa y el mismo Gabriel García Márquez. Balcells ayudó a que toda una generación de escritores latinoamericanos publicase sus obras en establecidas editoriales y obtuvieran un perfil internacional. También sabemos que García Márquez durante toda su vida estuvo implicado con la industria del cine. Comenzó escribiendo guiones en México con Carlos Fuentes como por ejemplo El gallo de oro (1964) y Tiempo de Morir (1965) y más tarde incluso reescribió y adaptó sus propias obras para el cine con directores como Fernando Birri, Tomás Gutiérrez Alea, Jaime Humberto Hermosillo y Ruy Guerra en los 80. Casi a la vez que publicó la novela El amor en los tiempos del cólera en 1985, se fundó en la Habana la 'Fundación del nuevo cine latinoamericano' con García Márquez como presidente con la intención política de crear un cine alternativo al creado en los Estados Unidos (Rajadhyaksha 1998: 419). Resulta irónico que años más tarde y al fin de su vida García Márquez vendiera los derechos para la adaptación de El amor en los tiempos del cólera a una compañía cinematográfica norteamericana.

La gran inversión en la producción como el elenco, la música, el vestuario y la cinematografía sugieren que la película siguió lo que se denomina 'blockbuster strategy'. Según Anita Elberse, esta estrategia funciona en la industria cultural para maximizar el impacto y aumentar los beneficios: "The hightest-performing entertainment business take their chances on a small group of titles and turn those choices into successes" (2013: 3-4). Cuanto más dinero se arriesga, más se recoge o al menos esa es la idea. la producción tuvo una gran inversión semejante a películas como The Hangover o The Blind Side sin llegar a los gastos de producción como en películas que han adaptado a Harry Potter cuyos costos de producción ascienden a más de 150 millones de dólares (2013: 21). Como Néstor García Canclini ha aseverado "el cine reciente se inserta de dos maneras en esta utilización cosmopolita de lo local" (2002: 80) y sin embargo, la estrategia de glocalizar la literatura latinoamericana ha sido en muchos casos fallido para Hollywood.

Con la promoción en mente, se propuso el libro para el círculo de lectura Oprah's Book Club, en el cual participan millones de lectores en una "discusión en masa" mediante la televisión y el internet. Según Katheleen Rooney, Oprah es «a serious American intellectual who pioneered the use of electronic media, specifically television and the Internet, to take reading - a decidedly nontechnological and highly individual act — and highlight its social elements and uses in such a way to motivate millions of erstwhile non-readers to pick up books» (2005: xii).

Aunque haya también duros críticos del club literario de Oprah y su superficialidad, no cabe duda que sus promociones han resultado en ventas millonarias de libros al ser promocionados en la televisión y en su plataforma interactiva en el internet (Flamm, 2011). En el caso de la película de Newell, el club de Oprah, comentó el libro de García Márquez reeditado por Vintage el 5 de octubre del 2007 y con la intención de aumentar la audiencia del filme Love in the Time of Cholera, cuya primicia fue el mismo mes. Convertido en un producto de consumo global, sin embargo, la adaptación 
al cine sobre la novela no tuvo la aceptación de los públicos masivos, ni de la crítica, a pesar de tener todo a su favor. Irónicamente, la intervención de Oprah volvió a poner el libro en las listas de más vendidos por veintiséis semanas en el New York Times Best Seller List en el 2008 y en el 2011 fue nombrado uno de los “Top 10 Best Selling Oprah’s Book Club books” (Bussone, 2002).

Ya hemos apuntado algunos de los cambios que se dieron en la adaptación y ahora apuntamos cómo la crítica recibió el filme para terminar de entender otros aspectos de la adaptación que hicieron que fallara su recepción. La diferenciación entre narración y su enunciación fílmica nos puede ayudar a entender esta comedia de errores de traducción. Algunas reseñas se acercan al tema sin totalmente enunciarlo. Para uno el problema de la película es el realismo que no representa la extravagancia del material garciamarquiano:

\footnotetext{
Alas, the movie doesn't have that rich allusiveness or strong dose of foolish passion. It's a well-crafted, handsome period piece, and pleasant to watch, but the intensity of an obsessional style-something that matches Florentino's crazy single-mindedness-is beyond Newell's range. The director of "Donnie Brasco" and "Four Weddings and a Funeral" doesn't paint with the camera; he doesn't seize on certain visual motifs, as he should, and turn them into the equivalent of a lover's devotion to fetishes. He's a realist handling comically extravagant material, and he does little more than competently frame a mixed set of performances (Denby, 2007).
}

En otras palabras, según la crítica, lo que se nos presenta es una realidad desprovista de la extravagancia y la hipérbole, sin lo grotesco e irónico de la novela. La película copia los diálogos y sintetiza la historia de amor pero desecha los detalles grotescos y disonantes en la historia que precisamente hacen que el lector entienda la historia más allá del realismo. Como dice la cubierta del DVD: “How Long Would You Wait for Love?”, esta versión convierte la historia de Florentino Ariza y Fermina Daza en la narrativa central de la narración, en la que Florentino espera 51 años, 9 meses y 4 días para que se muera su esposo Juvenal Urbino y declarar su amor eterno de nuevo (García Márquez, 1985a: 77). Como fue anunciado por el productor a los medios: "Stone Village Pictures is reportedly paying the Colombian Nobel laureate between one and three million dollars to make a movie of what producer Scot Steindorff recently termed "the best love story ever told, next to Romeo and Juliet”“ (Tuckman, 2004). Esto constituye una perspectiva tan trivial que deja las múltiples evocaciones de la vejez, la guerra y la violencia, el comentario sobre el machismo, el juego entre la razón y el romanticismo, la opresión racial en el mundo postcolonial, la modernización y la destrucción natural de las poblaciones del Río Magdalena fuera de la narración. También se intenta proporcionar un significado fijo y facilón que no ofrece suficiente tensión para mantener la atención del público, puesto que la novela usa el tema del amor eterno para hablarnos del poder patriarcal, del eurocentrismo, de la vejez y de la historia. Por otro lado, como Doru Pop apunta, pero sin elaborar más allá, "Love in the Time of Cholera has too close a connection to the "literal" meaning of the book, and by this it does not give space to any of the "natural elements" of cinema to come into place" (Pop, 2008: 212). Según Pop, Las otras razones del profundo fracaso de la película es el mal maquillaje y que los personajes hablen el inglés con un acento español horrible (2008: 214). Sin embargo, el problema pareciera más la simplificación de la trama en una historia de amor puramente realista, porque precisamente ese 
realismo no coincide con la estética de la exageración de la novela y la costumbre de recrear el pasado de manera proustiana, como apunta Hart, para repasar el pasado como parte de la memoria (2010: 133$34)$.

El director diligentemente intentó incorporar la complejidad de los personajes y una variedad de historias secundarias posibles para ambientar la historia principal, pero todavía le sigue faltando los otros grandes temas de la novela. Como dice la reseña:

By following the story line of Gabriel García Márquez's novel, "Love in the Time of Cholera," directed by Mike Newell, eventually arrives at a lovely place, but it arrives limping. Small but nagging problems drag it down, such as weird acting choices, bizarre casting and strange aging makeup. These problems aren't big enough to ruin the movie, but stretched out over 139 minutes, they're more than enough to take a film that should have soared and render it earthbound (LaSalle, 2007).

Las actuaciones intentan presentar la ironía y el absurdo del original, pero no funcionan, puesto que la historia pretende el realismo romántico que precisamente García Márquez deconstruye con disonancia. De acuerdo con Alessandro Rocco, «there seems to be a fundamental structural weakness in the construction of the film's plot and the narrative rhythm [...] the story seems to become stranded in a succession of events lacking any issue or tension that can serve as the principal dynamic and keep the spectator emotionally involved» (Rocco, 2014: 178).

De nuevo, eso puede ser parte del asunto, pero la sucesión de eventos en la novela pone en evidencia 'la realidad' como ficciones o como invenciones de los personajes, la sociedad o el mismo narrador. Es por tanto que la película se queda corta con respecto a esta técnica.

En parte es un problema de focalización entre la escritura y la adaptación de la misma es porque García Márquez crea un narrador omnisciente e irónico-humorista que incorpora lo exagerado en lo real. De esa combinación salen chispas que recíprocamente critican y cuestionan ambos extremos. Como indica M. Keith Booker, el narrador en la novela es un narrador no fidedigno que nos engaña con su seductora narración y lo que nos cuenta sobre el amor profundo de los personajes lo deconstruye páginas después (1993: 183). El narrador afirma constantemente que la relación entre Juvenal y Fermina es perfecta y feliz, pero hacia el final de la novela se nos revela la aventura amorosa de Juvenal con la mulata Barbara Lynch y la otra posibilidad con Lucrecia. Urbino tiene un carácter controlador y manipulador sobre su esposa que se va filtrando en la narrativa en pequeños detalles que nos hace empezar a cuestionar la verdad o el realismo de la historia. Si Juvenal Urbino representa la ciencia europea y el pragmatismo, Florentino representa el romanticismo europeizante y la irracionalidad. Ambos son modelos extranjeros, que según Moraña, "enact the limit of nineteenth century ideologies of scientific progress and romanticism. The anachronistic plot of romantic love taken to the point of parody is deployed by the author as a critique of fin de siècle modernity" (1990). Entonces, de nuevo la parodia y los otros significados son claramente desplazados en la película para conseguir esa unidad romántica. En otras palabras, el problema fundamental de la adaptación es reproducir la novela en su contenido, pero no en su espíritu anti-romántico.

En la novela tenemos constancia de innumerables ejemplos en los que Juvenal quiere controlar todo y sin embargo esas cosas se pierden en la película, porque lo importante de la narrativa es la 
persistencia del amor de Florentino y Juvenal solamente sirve para enfatizar el casamiento de conveniencia. Florentino cree en la palabra literaria y trata a todo como si fuera un personaje en un poema o novela. También, tenemos que el narrador nos cuenta algo para enseñarnos más tarde que nos ha seducido y engañado. Como dice Isabel Alvárez-Borland:

[...] this constant tongue-in-cheek attitude on the part of the narrator towards his own novelistic world cautions the reader about the possibility of other readings which might go beyond the story's events. As we shall see, by means of an acute sense of irony (Garcia Marquez' trademark), the conventions of the novelistic genre are constantly debased. This Cervantine (and Flaubertian) technique serves to prevent the reader from becoming exclusively immersed in the text's mimetic plot (1991: 179).

Entonces, como lectores de la novela, no podemos pensar que la historia de amor es específicamente fidedigna. Sobre todo, cuando sabemos que la manera de esperar por su amor de Florentino es acostarse con más de 600 mujeres. Esa disonancia en la 'historia realista de amor' idealizado crea una serie de ironías en la novela, pero crea un desconcierto en la película que pretende presentarlo como 'real' o 'verosímil' sin parecer hipócrita o mentiroso al personaje.

Como nos dice un reseñador nuevo zelandés:

While in the novel Florentino's longing and undying love for Fermina is endearing, in the film it becomes stalker-like and in modern times a restraining order would be just around the corner. His desperation becomes painful to watch, and his conquests of random women in an attempt to ease his sorrow do nothing to help the viewer to empathise with him (Flicks.co.nz, 2008).

En la película que debería ser la historia más romántica desde Romeo y Julieta, Florentino no puede convertirse en el héroe romántico que pretende la gran narrativa de la película ya que es un personaje contradictorio e incluso aberrante. La película borra dos cosas importantes del personaje que lo hace incluso más siniestro: La niña de 14 años que es puesta bajo su tutelaje y es seducida por el viejo Florentino, se suicida en la novela al descubrir que éste está enamorado de Fermina. Como dice otro reseñador de la película:

Trying (where Márquez succeeds) to convey romance, social commentary, and comedy, the film becomes a muddied blend of emotion. Funny when it's supposed to be serious, confusing when it's supposed to be poetic, and awkward when it's supposed to be romantic, every twist is a near miss. On the page, Florentino's affairs are heartbreaking, comedic, and surreal, yet onscreen, his incessant sexual encounters caused one audience member behind me to remark, "That was like a period-piece Porky's." Not surprisingly, it's better to just read the book (Burton, 2007).

El intento del realismo rompe la posibilidad de una lectura contraria: El amor es una ilusión, una creación en la mente de Ariza. La historia constituye una parodia del amor cortés. Pero en la película se vuelve ridículo en al intento de hacer el amor cortés verosímil.

En conclusión, podemos afirmar que la adaptación es fidedigna en muchos aspectos: representa la época con precisión, dramatiza los diálogos memorables de García Márquez y pinta a los personajes de forma fiel (Newell). Sin embargo, el juego narrativo de la novela exige una problematización de la realidad a través de aspectos que no se pueden explicar de forma 'realista' y que entrarían dentro del ámbito del realismo mágico. Tampoco la versión fílmica establece un juego de perspectivas en la que el narrador y el lector se convierten en cómplices como en la novela. La realidad no es lo que es, el 
amor puede que no sea el tema sino el medio para ahondar en la realidad. No nos podemos fiar del narrador, ni de los personajes, ni de la memoria. Mientras Hollywood trata de crear un producto asequible y global (the national historical romance), la novela se resiste a esa representación realista que transforma la historia mágica en mundana. García Márquez plantea que el amor en los tiempos del cólera no es lo que parece, ni el cólera es lo que pretende ser.

\section{Bibliografía citada}

Álvarez Borland, Isabel (1991): «Interior Texts in El amor en los tiempos del cólera», Hispanic Review, 59/2, pp. 175-186.

BooKer, M. Keith (1993): «The Dangers of Gullible Reading: Narrative as Seduction in García Márquez' Love in the Time of Cholera», Studies in 20th \& 21st Century Literature, 17/2, pp. 181-195.

Bell-VilladA, Gene H. (1990): García Márquez: The Man and His Work. Chapel Hill and London, The U. of North Carolina Press.

Bourdieu, Pierre (1993): The Field of Cultural Production: Essays on Art and Literature. Randal Johnson, ed. Cambridge, UK, Polity.

Burton, Toddy (2007). «Film Review: Love in the Time of Cholera». The Austin Chronicle, en https://www.austinchronicle.com/calendar/film/2007-11-16/560410/en (última consulta, 1-112017).

Bussone, Angela (2002): Gabriel García Márquez: A biography, en http://www.hyperink.com/ Major-Accomplishments-And-Awards-b1489a12 (última consulta, 1-11-2017).

CooK, Deborah (1996): The Culture Industry Revisited: Theodor W. Adorno on Mass Culture. Lanhan, Maryland, Rowman and Littlefield.

DENBY, David (2007): “Obsessed”, The New Yorker, en https://www.newyorker.com/magazine/2007/ 11/19/obsessed (última consulta, 1-11-2017).

ElBERSE, Anita (2013): Blockbusters: Hit-Making, Risk-Taking, and the Big Business of Entertainment. New York, Henry Holt.

FAHY, Tom (2003): Gabriel García Márquez's Love in the Time of Cholera. New York, Bloomsbury.

FlAMM, Matthew (2011): «Publishers Say Farewell to Oprah Book Club Boon», Crain's New York Business, en http://www.crainsnewyork.com/article/20110520/FREE/110529985 (última consulta, 1-11-2017).

FLICKS.CO.Nz (2008): «Love in the Time of Cholera», en https://www.flicks.co.nz/movie/love-in-thetime-of-cholera/ (última consulta, 1-11-2017).

GARCÍA CANCLINI, Néstor (2002): Latinoamericanos buscando lugar en este siglo. Buenos Aires, Paidós.

GARCÍA MÁRQUEZ, Gabriel (1985a): El amor en los tiempos del cólera. New York, Vintage Español, 2003. 
(1985b): «La penumbra del escritor de cine», en Eduardo GARCÍA Aguilar, García Márquez: La tentación cinematográfica. Mexico, Universidad Nacional Autónoma de México.

HART, Stephen M. (1982): «Magical Realism in Gabriel García Márquez's Cien años de soledad», INTI, 16/17, pp. 37-52.

(2010): Gabriel García Márquez. London, Reaction.

Lasalle, Mick (2007): «Review: 'Cholera' Devoid of the Delirium of Love», San Francisco Gate, en http://www.sfgate.com/movies/article/Review-Cholera-devoid-of-the-delirium-of-love-3235 926.php (última consulta, 1-11-2017).

«LOVE IN THE TIME OF CHOlERA ADAPTED FOR SCREEN» (2007): Talk of the Nation, National Public Radio, en http://www.npr.org/2007/11/13/16259056/love-in-the-time-of-cholera-adapted-forscreen (última consulta, 1-11-2017).

«LOVE IN THE TIME OF CHOLERA - TRAILER» (2007): «Love in the Time of Cholera», en http://www. imdb.com/title/tt0484740/videoplayer/vi3316711705?ref_=tt_pv_vi_aiv_1 (última consulta, 3112-2017).

MAnZANAS, Ana María (2009): «Chapter II: Romance, The Imaginary, and Magical Realism», en Jesus Benito, Ana María ManZanas, y Ana Begoña Simal, eds., Uncertain Mirrors: Magical Realisms in U.S. Ethnic Literatures. Amsterdam, Rodopi, pp. 65-33.

MCFARlane, Brian (1996): Novel to Film: An Introduction to the Theory of Adaptation. Oxford, Clarendon Press.

Millington, Mark I. (2010): «García Márquez's novels of love», en Philip Swanson, ed., The Cambridge Companion to Gabriel García Márquez. Cambridge, Cambridge UP, pp. 113-128.

MorAÑA, Mabel (1990): «Abstract: Modernity and Marginality in Love in the Time of Cholera», Studies in $20^{\text {th }}$ Century Literature, 14/1, pp. 27-43.

MURRAY, Simone (2012): The Adaptation Industry: The Cultural Economy of Contemporary Literary Adaptation. New York, Routledge.

NAREMORE, James (2000): «Introduction: Film and the Reign of Adaptation», James NAREMORE, ed., Film Adaptation. New Brunswick, NJ, Rutgers University Press, pp.1-16.

NEWELL, Mike (2007): Love in the Time of Cholera. DVD.

PoP, Doru (2008): «About the Cinematic Adaptation of Love in the Time of Cholera. Notes on Cinema and Literature», Caietele Echinox, 14, pp. 210-215.

Rajadhyaksha, Ashish (1998): «Realism, Modernism, and Post-Colonial Theory», en John HiLl y Pamela Church GiBson, eds., The Oxford Guide to Film Studies. Oxford, Oxford University Press, pp. 413-425.

Rocco, Alessandro (2014): Gabriel García Márquez and the Cinema. Woodbridge, Tamesis Books. RoONEY, Kathleen (2005): Reading with Oprah: The Book Club that Changed America. Fayetteville, The U. of Arkansas Press.

Schwarzbaum, Lisa (2007): «Love in the Time of Cholera», Entertainment Weekly's, en http://ew.com/article/2007/11/14/love-time-cholera-2/ (última consulta, 1-11-2017). 
«SCREENWRITER ADAPTS 'LOVE' FOR THE SILVER SCREEN» (2007): «Screenwriter Adapts 'Love' for the Silver Screen», All Things Considered, National Public Radio, en http://www.npr.org/ templates/story/story.php?storyId=16203866 (última consulta, 1-11-2017).

SOMMER, Doris (1990): «Irresistible Romance: The Foundational Fictions of Latin America», en Homi K. BHABHA, ed., Nation and Narration. London, Routledge.

(1991): Foundational Fictions: The National Romances of Latin America. Berkeley, University of California Press.

STAM, Robert (2000): «Beyond Fidelity: The Dialogics of Adaptation», en James NAREMORE, ed., Film Adaptation. New Brunswick, NJ, Rutgers University Press, pp. 54-76.

StePHENFOLLOWS.COM (2014): «What Are the Highest-Grossing Movie Adaptations?», Stephen Follows: Film Data and Education, en https://stephenfollows.com/highest-grossing-movieadaptations/ (última consulta, 1-11-2017).

TuCKMAn, Jo (2004): «Author Green Lights Cholera Film», The Guardian en https://www. theguardian.com/world/2004/aug/09/books.film (última consulta, 1-11-2017)

WiLliams, Raymond Leslie (1989): «The Visual Arts, the Poetization of Space and Writing: An Interview with Gabriel García Márquez», PMLA, 104/2, pp. 131-140. 